\title{
PENGAMANAN RUANG DENGAN PENGENALAN POLA WAJAH SECARA REALTIME MENGGUNAKAN ALGORITMA VIOLA JONES
}

\author{
Taufiq Hidayat ${ }^{1}$, Moch Lutfi ${ }^{2}$ \\ Universitas Yudharta Pasuruan \\ Jl. Yudharta No. 07 (Pesantren Ngalah) Sengonagung Purwosari Pasuruan \\ Telp./ Fax. 0343-611186 \\ e-mail: taufighusen119@gmail.com
}

\begin{abstract}
Abstrak
Deteksi wajah banyak diperlukan di berbagai cabang keamanan, seperti dalam aspek pengawasan, keselamatan, verifikasi dan identifikasi. Dalam bidang keamanan, pengenalan wajah banyak diperlukan untuk otentifikasi, misalkan otentifikasi pelaku kriminal, seperti deteksi terhadap pelaku teror, pencegahan terhadap terpidana korupsi yang hendak melarikan diri ke luar negeri dll.Dalam penelitian computer vision banyak metode yang bisa digunakan untuk deteksi wajah, salah satunya adalah dengan menggunakan metode Viola Jones. Metode ini digunakan untuk mendeteksi wajah dengan menggunakan klasifikasi berdasarkan pendekatan algoritma AdaBoost dan Haar Cascade. Pada algoritma Viola Jones ini, metode Adaboost digunakan untuk menjadi penentu nilai ambang batas, sedangkan Haar Cascade digunakan untuk klasifikasi area sub windows. Tujuan penelitian ini yaitu penerapan metode Viola Jones dalam mendeteksi wajah seseorang, yang dapat dijadikan sistem keamanan tambahan dalam suatu ruangan. Hasil pengujian untuk mendeteksi wajah dengan Viola Jones adalah akurasi ketika wajah dalam posisi frontal dengan webcam sebesar $100 \%$ dengan waktu deteksi kurang dari 1 detik. Sedangkan batas kemiringan maksimum \pm 70 dan jaraknya $20-120 \mathrm{~cm}$. Pengujian sistem menggunakan metode Eigenface diperoleh nilai akurasi sebesar 90\%.
\end{abstract}

Kata Kunci :Deteksi Wajah, Viola Jones, Haar Cascade.

\section{Pendahuluan}

Deteksi wajah banyak diperlukan di berbagai aspek keamanan, seperti dalam aspek pengawasan, keselamatan, verifikasi dan identifikasi. Dalam bidang keamanan, pengenalan wajah banyak diperlukan untuk otentifikasi, misalkan otentifikasi pelaku kriminal, seperti deteksi terhadap pelaku teror, pencegahan terhadap terpidana korupsi yang hendak kabur, dan terhadap gembong narkoba. Selain hal-hal tersebut, pengenalan wajah juga bisa digunakan untuk identifikasi, seperti identifikasi terhadap mayat yang ditemukan disuatu tempat. Oleh karena itu, dalam penelitian ini membahas tentang suatu gabungan metodologi antara metodologi untuk deteksi wajah dan metodologi untuk mengenali wajah yang masuk dalam kategori real time face recognition. (Jusia, 2016).

Pada real time face recognition, terdapat dua situasi utama yang dilakukan, yaitu pengenalan dan deteksi wajah Dalam keamanan suatu tempat, diperlukan suatu pedeteksian yang cepat dalam segi waktu, oleh karena itu diperlukannya sebuah aplikasi yang dapat mendeteksi wajah seseorang secara real time. Dalam penelitian computer vision banyak metode yang bisa digunakan untuk deteksi wajah, contohnya dengan menggunakan algoritma Viola Jones. Metode ini digunakan dengan bantuan klasifikasi berdasarkan pendekatan algoritma AdaBoost dan Haar Cascade. Pada algoritma Viola Jones ini, metode Adaboost digunakan untuk menjadi penentu nilai ambang batas, sedangkan Haar Cascade digunakan untuk klasifikasi area sub windows.

Berdasarkan uraian diatas, maka diperlukan sebuah: "SISTEM PENGAMANAN RUANGAN DENGAN PENGENALAN WAJAH SECARA REALTIME'. Dengan adanya aplikasi ini diharapkan akan menjadi sistem pendukung keamanan dan pengawasan suatu ruangan. 


\section{Metode penelitian}

Objek wajah dicari menggunakan Viola Jones dimana citra yang di-capture dari webcam akan diseleksi fitur kemudian dilakukan proses perhitungan integral image. Dengan Adaptive Boosting dan kombinasi Cascade Classifier akan mempercepat pendeteksian objek wajah. Jika wajah terdeteksi, akan dilakukan penggambaran garis persegi pada wajah tersebut.
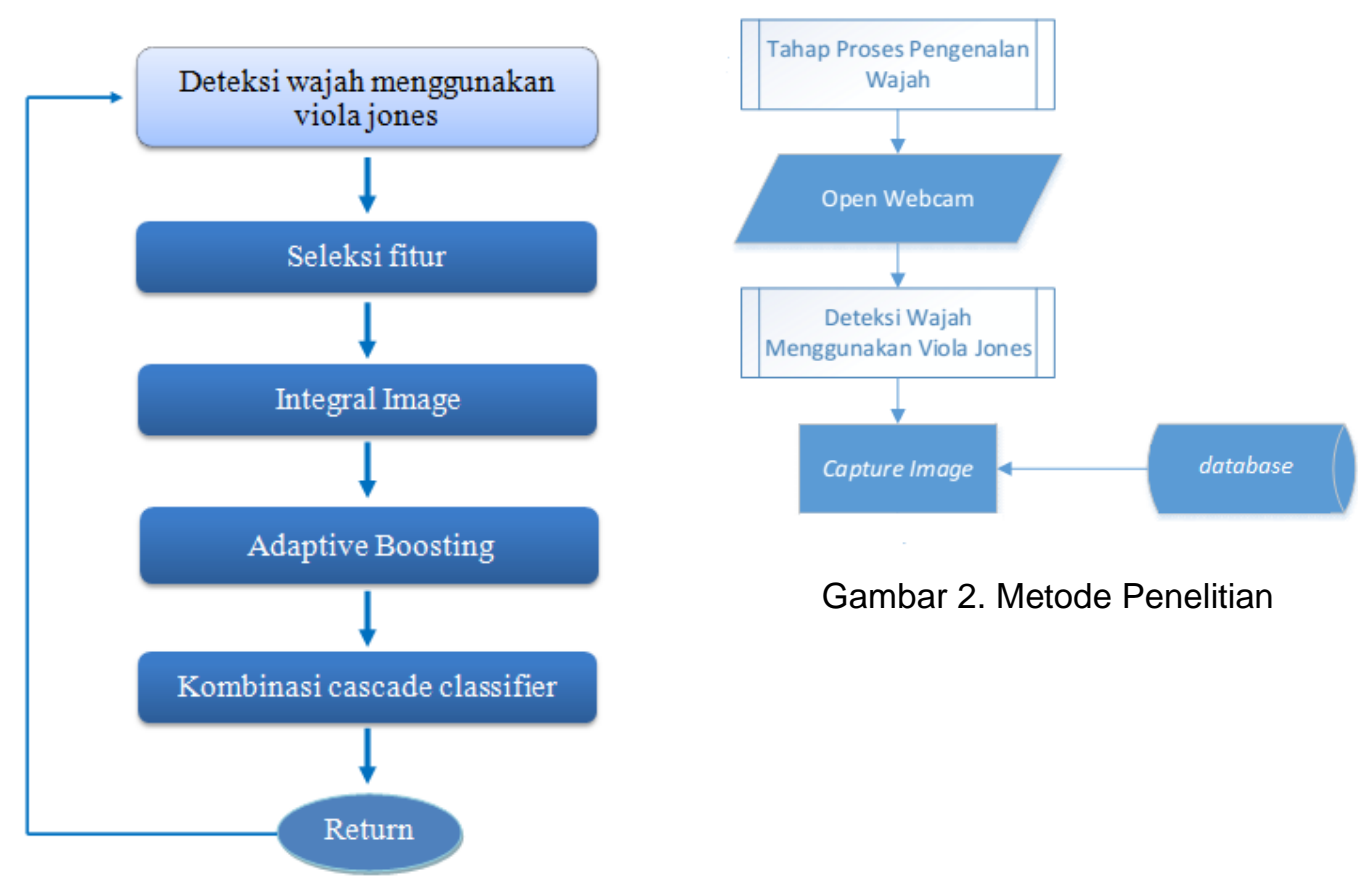

Gambar 2. Metode Penelitian

Gambar 1. Metode Penelitian

\section{Hasil dan Analisis}

Pada tahap ini, akan dilakukan uji coba menggunakan Matlab R2014a serta pembuatan desain tampilan deteksi wajah dan disajikan pada gambar berikut.

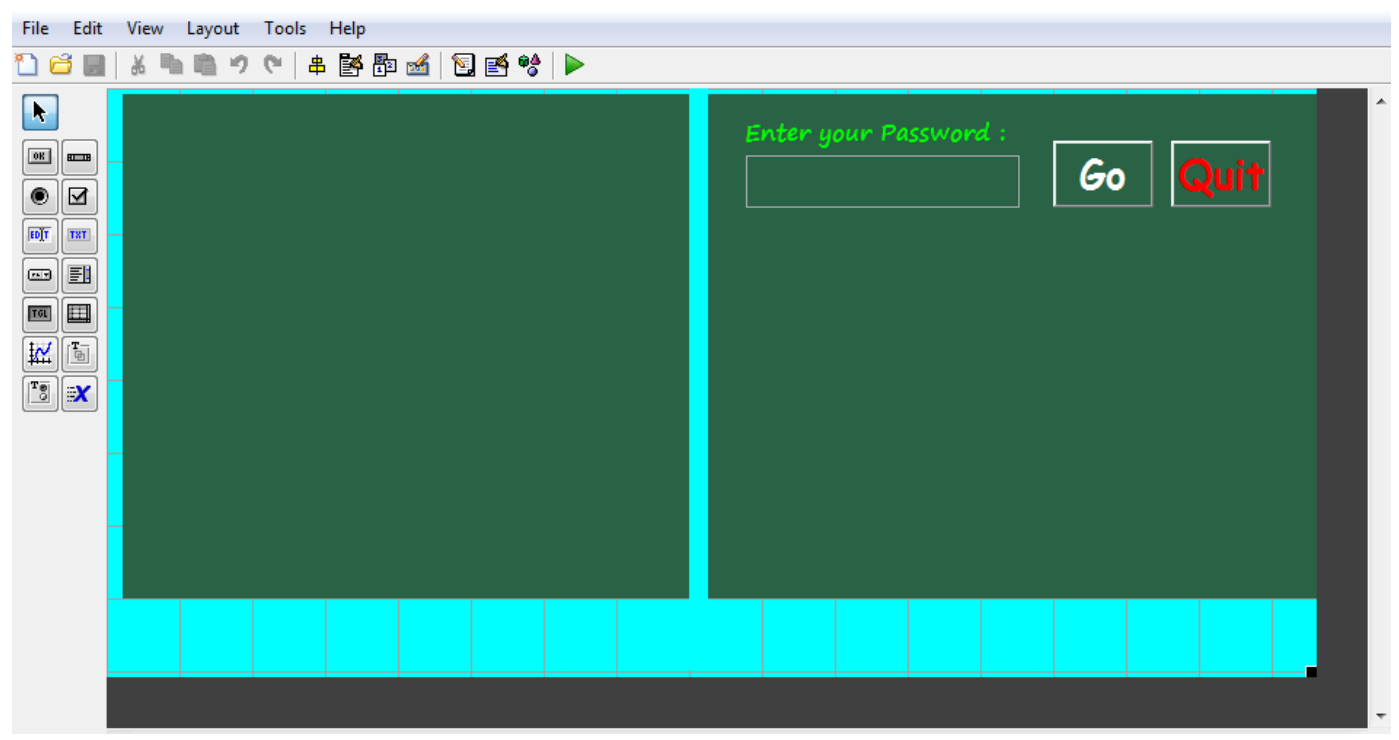

Gambar 3 Desain Tampilan Antarmuka Deteksi Wajah 


\subsection{Hasil Uji Coba}

Pengujian yang dilakukan ada 2, yaitu:

a. Pengujian untuk mendeteksi wajah dengan metode Viola Jones.

Pengujian dilakukan berdasarkan jarak, pencahayaan, kemiringan, wajah terhalang objek lain, beberapa wajah, dan berdasarkan karakter objek yang menyerupai wajah.

Table 1. Hasil Pengujian

No Gambar Hesimpulan

1.
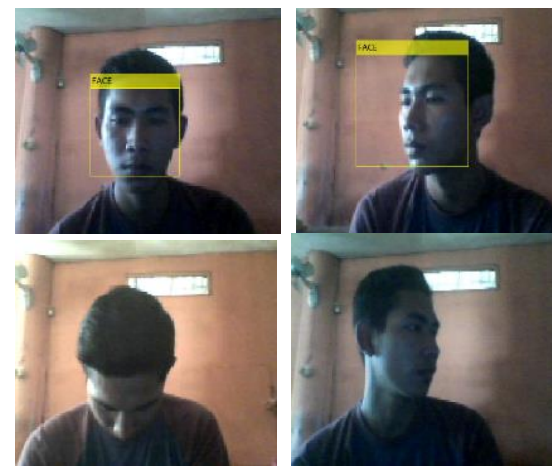

2.
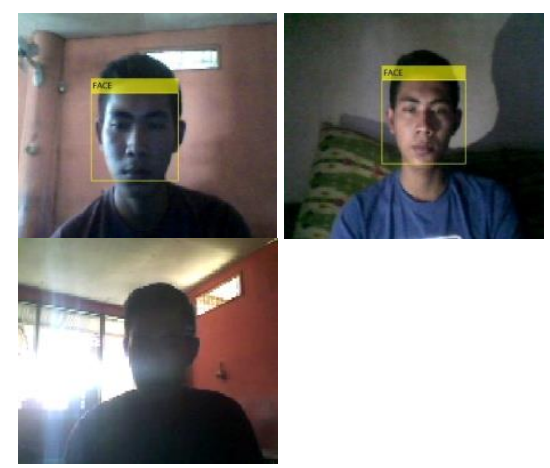

3.
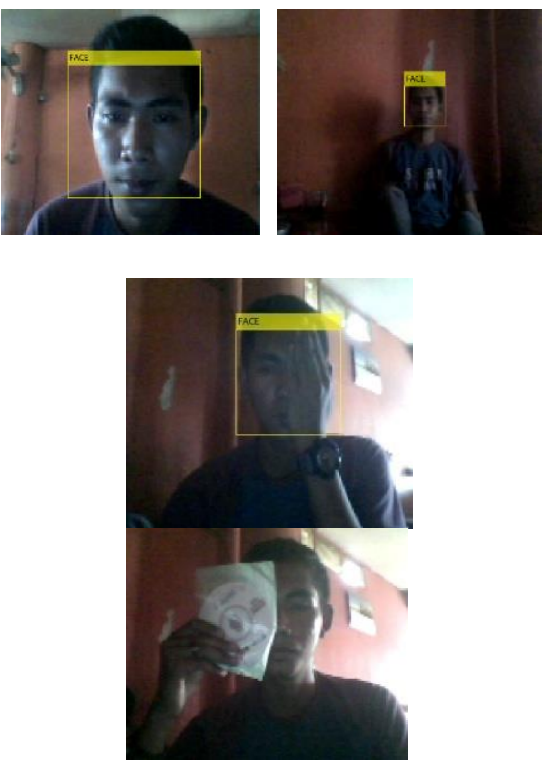
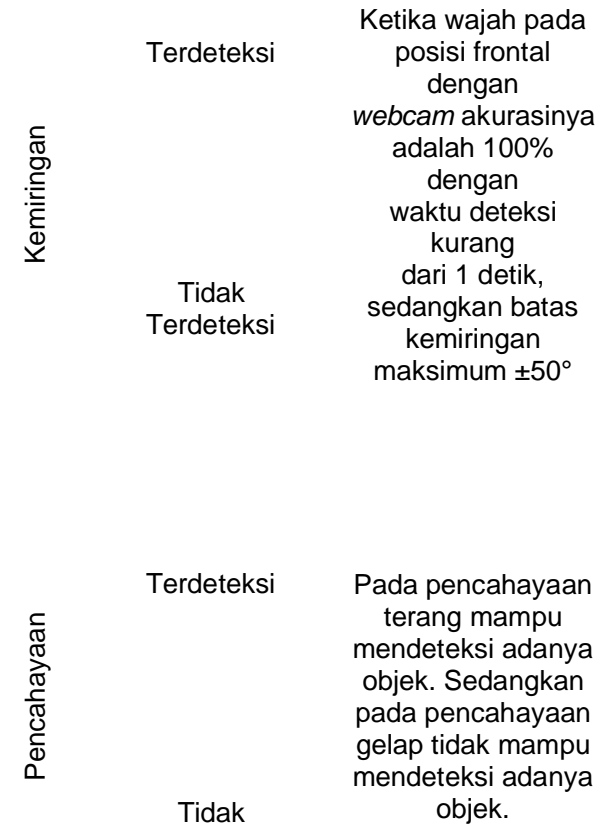

产 Terdeteksi

Jarak terdekat 20 $\mathrm{cm}$, pada jarak 200 $\mathrm{cm}$ masih bisa terdeteksi.

Terdeteksi

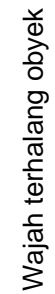

Tidak

Terdeteks mampu mendeteksi objek wajah meskipun terhalang selamanya

konturnya sama dengan kontur wajah. 


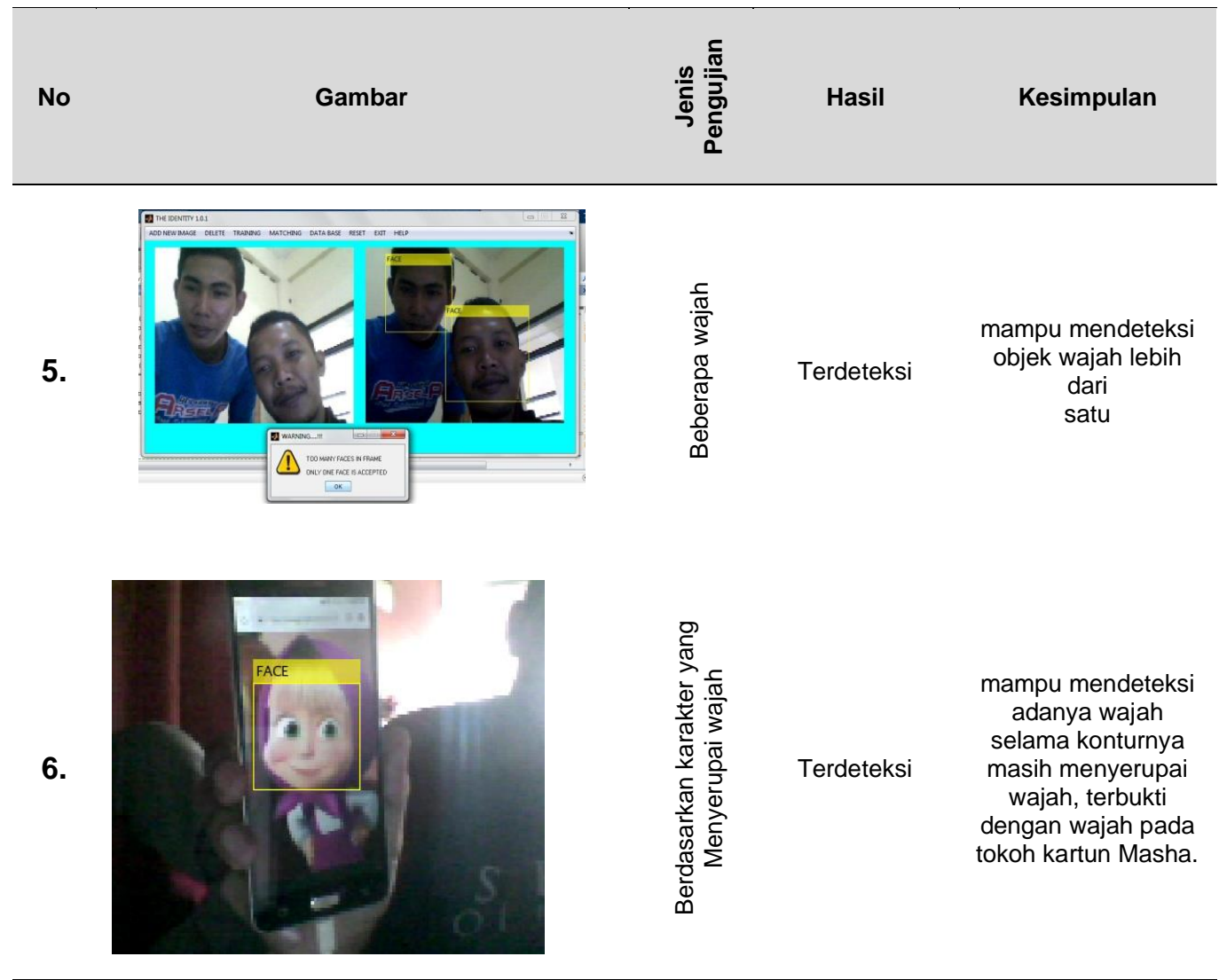

b. Pengujian aplikasi yang dibuat

Pengujian dilakukan 10 kali percobaan pada sebuah citra yang berukuran $300 \times 300$ piksel. Pengujian dilakukan dalam berbagai ekspresi wajah. Dari 10 percobaan hanya ada 1 citra wajah yang tidak dikenali. Sehingga tingkat akurasi sistem sebesar $90 \%$. Hal ini dikarenakan wajah tersebut tidak terdapat didalam database.

Tabel 2. Uji Coba Menu Aplikasi

\begin{tabular}{|c|c|c|c|}
\hline NO. & MENU & $\begin{array}{l}\text { KONDISI YANG } \\
\text { DIHARAPKAN }\end{array}$ & HASIL \\
\hline 1. & $\begin{array}{l}\text { ADD NEW } \\
\text { IMAGE }\end{array}$ & $\begin{array}{l}\text { Mengambil citra menggunakan } \\
\text { webcam }\end{array}$ & Berjalan Baik \\
\hline 2. & DELETE & $\begin{array}{l}\text { Menghapus citra wajah yang } \\
\text { tersimpan, baik dengan cara } \\
\text { satu per satu maupun multiple }\end{array}$ & Berjalan Baik \\
\hline 3. & TRAINING & $\begin{array}{l}\text { Uji coba citra wajah sebelum } \\
\text { disimpan ke database }\end{array}$ & Berjalan Baik \\
\hline 4. & MATCHING & $\begin{array}{l}\text { Melakukan uji coba citra yang } \\
\text { sudah ada di database }\end{array}$ & Berjalan Baik \\
\hline 5. & DATABASE & $\begin{array}{l}\text { Menampilkan hasil capture } \\
\text { citra wajah beserta nama } \\
\text { orang yang memiliki citra } \\
\text { tersebut }\end{array}$ & $\begin{array}{l}\text { Berjalan } \\
\text { Kurang Baik }\end{array}$ \\
\hline 6. & RESET & $\begin{array}{l}\text { Mereset ulang axes tampilan } \\
\text { aplikasi }\end{array}$ & Berjalan Baik \\
\hline 7. & EXIT & Keluar dari aplikasi & Berjalan Baik \\
\hline 8. & HELP & $\begin{array}{l}\text { Menampilkan bantuan } \\
\text { penggunaan aplikasi }\end{array}$ & Berjalan Baik \\
\hline
\end{tabular}




\section{Kesimpulan}

1. Akurasi sistem ketika wajah pada posisi frontal dengan webcam sebesar $100 \%$ dengan waktu deteksi kurang dari 1 detik, sedangkan batas kemiringan maksimum $\pm 70^{\circ}$ dan jaraknya $20-120 \mathrm{~cm}$.

2. Faktor-faktor yang mempengaruhi hasil pengenalan pada sistem ini adalah pencahayaan, jarak capture antara objek wajah dan webcame serta distorsi (kemiringan) wajah pada saat proses capture dilakukan.

3. Dari pengujian sebanyak 10 kali didapatkan sebanyak 9 citra wajah berhasil dikenali sesuai dengan database. Sedangkan 1 citra wajah tidak berhasil dikenali. Tingkat akurasi sistem sebesar $90 \%$.

4. Wajah yang tidak berhasil dikenali dikarenakan wajah tersebut tidak terdapat dalam database.

\section{Saran}

Penelitian yang dilakukan ini sangat sederhana dan masih banyak kekurangannya, oleh karena itu penulis menginginkan agar kedepannya dapat dibangun sebuah sistem yang dapat mengenali wajah dengan tingkat kemiripan yang lebih akurat, diantaranya adalah sebagai berikut:

1. Diharapkan membangun suatu sistem yang dapat mengenali wajah tidak hanya dari tampak depan, tetapi juga dapat mengenali dari tampak samping.

2. Sebaiknya perlu dilakukan penyempurnaan dalam intesitas cahaya, sehingga di tempat yang agak redup pencahayaannya, proses pengenalan wajah dapat berjalan dengan baik.

3. Agar pengembangan sistem selanjutnya, pengenalan wajah ini dapat mengenali berbagai macam ekspresi wajah pengguna, walaupun data orang yang ada di database sangat banyak.

\section{References}

[1] Dharmawan, A. B., \& Lina. (2015). Sistem Pintu Otomatis Berdasarkan Pengenalan Wajah Menggunakan Metode Nearest Feature Line. 6.

[2] Ghafur, U. J. (N.D.). Pengolahan Citra Digital . 7.

[3] Jusia, P. A. (2016). Face Recognition Menggunakan Metode Algoritma Viola Jones Dalam Penerapan Computer Vision. 13.

[4] Kurniawati, A. T., \& Rama, A. R. (2015). Aplikasi Pengenalan Wajah Menggunakan Metode Eigenface Dengan Bahasa Pemrograman Java. 12.

[5] M. Miftakul Amin, M. E. (N.D.). Pengolahan Citra Digital. Morfologi (Lanjutan) , 18.

[6] Publishing, A. (2014). Pengolahan Citra Digital. 90.

[7] Puri, F. T. (2011). Analisis Algoritma Eigenface(Pengenalan Wajah) Pada Aplikasi Kehadiran Pengajaran Dosen.

[8] Putro, M. D., Adji, T. B., \& Winduratna, B. (2015). Sistem Deteksi Wajah Dengan Menggunakan Metode Viola-Jones. 71.

[9] S.Y Iriyanto, P., \& M.Kom, T. Z. Pengolahan Citra Digital (Digital Image Processing). Aura Publising.

[10] Salamun, \& Wazir, F. (2016). Rancang Bangun Sistem Pengenalan Wajah Dengan Metode Principal Component Analysis. 18. 